\title{
Modelling Conflict within the Social Networks of Large Multi-Vendor Software Projects using Communicating Stream X-Machines
}

\author{
Richard Alun Williams \\ Department of Management Science, Lancaster University Management School, LA1 4YX, UK \\ r.williams4@lancaster.ac.uk
}

\section{Extended Abstract}

There continue to be failures in the management of large IT projects, with anecdotal evidence from the media suggesting that most large public sector projects are not delivered to budget or on time. The fact that we continue to incur failures in managing large IT implementations should come as no surprise however, as they contain a number of areas of risk, ranging from the detailed technical requirements, to the overly ambitious timescales, and the need for large numbers of individual commercial organisations to seamlessly work together in a symbiotic manner. Indeed, some of the larger IT implementations consist of hundreds of customer and third-party team members, who are organised into multiple project teams, and may be located across different geographies and time zones.

With this in mind, it has recently been argued that the increasing size and complexity of these IT projects, leads them to exhibit the behaviours and traits of complex systems (Curlee and Gordon, 2011). Furthermore, with communication and trust issues being cited as the most important aspects of project success (PMI, 2008), it can be hypothesised that an important reason for failure may be the complexity that arises from social interactions within project environments (Hekkala and Urquhart, 2013). As such, we believe that an important reason for project failure may be the emergent behaviours that arise through the social networks within distributed, multiparty project environments; in particular around the areas of communication, commitment, trust, and the resulting conflict that emerges when/if trust breaks down. Conflict in this instance, is broadly defined as an awareness of incompatibilities or perceptions between individuals or groups, which is based on either discrepant views, incompatible wishes or interpersonal relationship issues (Jehn and Mannix, 2001).

Within this study, we have performed semi-structured interviews with project managers involved in large multivendor software implementations. This qualitative data has been analysed and transformed into a domain model, which has subsequently been used as the basis for an agentbased model using the concept of communicating stream X-
Machines (Balanescu et al., 1999). Through in silico experimentation, we are beginning to investigate the propagation of conflict through the social networks in multi-vendor software implementations. In particular, we are investigating the roles that intragroup conflict (between project team members) and intergroup conflict (between different project teams) play in the successful completion of large software implementation projects, involving multiple vendors distributed over multiple geographies and time zones. Our intention is to generate strategies to harness the complexity inherent to large IT projects, and communicate these back to the project management and IT consulting communities so that they may maximise the probability of project success.

\section{Acknowledgements}

This work was supported by a SAMS-ESRC-UKCES Management and Business Development Fellowship, grant No. ES/L002612/1.

\section{References}

Balanescu, T., Cowling, A., Georgescu, M., Holcombe, M., and Vertan, C. (1999). Communicating stream X-Machines are no more than X-Machines. Journal of Universal Computer Science, 5(9):494-507.

Curlee, W. and Gordon, R. (2011). Complexity Theory and Project Management. John Wiley \& Sons, New Jersey, USA.

Hekkala, R. and Urquhart, C. (2013). Everyday power struggles: Living in an IOIS project. European Journal of Information Systems, 22:76-94.

Jehn, K. and Mannix, E. (2001). The dynamic nature of conflict: A longitudinal study of intragroup conflict and group performance. Academy of Management Journal, 44(2):238-251.

PMI (2008). A Guide to the Project Management Body of Knowledge. Project Management Institute Inc, Pennsylvania, USA, 4 th edition.

Richard Alun Williams (2015) Modelling Conflict within the Social Networks of Large Multi-Vendor Software Projects using Communicating Stream X-Machines. Proceedings of the European Conference on Artificial Life 2015, p. 79 